\title{
APORTES DE LA
}

\section{ANTROPOLOGÍA A}

LAS CIENCIAS DE LA

EDUCACIÓN

Juan Bottasso, sdb.

Docente de la Universidad Politécnica Salesiana (Ecuador)

\section{Educación y cultura}

Todos los grupos humanos, desde los más reducidos, hasta los más numerosos y complejos, se preocupan por formar a los individuos que nacen en su interior de tal manera que asimilen las normas de conducta que son comunes a todos y así se conviertan en elementos útiles y leales al conjunto humano.

El ser humano, a diferencia de los demás mamíferos, es aquel que necesita por más tiempo de la asistencia de quienes lo engendraron. Sin un acompañamiento asiduo, que dura por muchos años, el pequeño ser no podría sobrevivir. Esta aparente debilidad acaba siendo su fortaleza. En efecto, el largo período de estrecha convivencia con los adultos, especialmente con la pareja que le dio la vida, le permite asimilar un patrimonio enorme de esos patrones de comportamiento, entre ellos: la forma de pensar, la dimensión social que es lo que denominamos cultura del grupo. 
Lo que llamamos educación no es más que la prolongación del proceso de socialización empezado en la familia. Todas las sociedades lo han practicado, mucho antes de que existieran los Ministerios de Educación de los Estados modernos. En sociedades menos estratificadas y con menos necesidad de especialización, este proceso exigía un lapso de tiempo menos prolongado. En la sociedad moderna la duración de este período se hace siempre más larga y exigente, pero, en definitiva, se reduce a lo mismo: preparar a los individuos para que puedan ubicarse en la sociedad.

Evidentemente, el continuo prolongarse de los años de la educación formal plantea serios problemas de tipo social, económico y psicológico, pero no este el tema del que quiero ocuparme en mi reflexión.

\section{El estímulo de la mundialización}

El fenómeno de la globalización no es nuevo: ya el Imperio romano, por ejemplo, constituía una suerte de mundo globalizado. Pero ahora el proceso ha alcanzado una aceleración que dificulta la posibilidad para que los individuos y los grupos asimilen los cambios y encuentren las respuestas a los nuevos retos.

La educación hoy está llamada no solamente a formar a individuos perfectamente capacitados para moverse al interior de su propia sociedad, sino también capaces de vivir en medio de culturas diferentes que, a menudo, chocan entre sí o, por lo menos, tienen cosmovisiones sumamente distantes.

Pensemos, por ejemplo, en grupos de migrantes islámicos trasplantados en Europa o, para limitarnos a Ecuador, en colonias de indígenas reubicados en los suburbios de las ciudades. Estos casos se harán siempre más 
frecuentes y ofrecerán a la antropología la oportunidad de prestar una ayuda a la ciencia de la educación.

\section{Una doble tensión}

El mundo en que vivimos, casi sin diferencias entre continentes y áreas geográficas, se ve atravesado por una doble tensión.

Por un lado, las comunicaciones que vehiculan los mismos modelos y proyectan las mismas imágenes; así como la industria que produce en serie, empujan hacia la homogenización y la estandarización de los estilos de comportamiento y de consumo.

Por otro lado, está regresando la curiosidad por explorar las diferencias y afirmar las identidades locales. Los particularismos son nuevamente recuperados en sus manifestaciones más diversas: lingüísticas, musicales, culinarias. Se redescubren fiestas, creencias, mitologías. Las Cámaras de Turismo no dejan de brindar su aporte para fortalecer la tendencia.

Claude Lévi Strauss hacía notar hace medio siglo que la mayoría de las poblaciones "primitivas" se autodefinen con un término que significa "los seres humanos", o con calificativos que suenan a autoexaltación, como, por ejemplo: los "buenos", los “auténticos", los "completos", sobreentendiendo que los demás no lo son. A menudo éstos son explícitamente descalificados como los "malvados", los "piojos", los "simios". Hasta cuando las diferentes culturas vivían relativamente aisladas, este etnocentrismo exacerbado no causaba sino conflictos limitados y locales.

Pero, en la actualidad, los desplazamientos de grandes masas y la información, que pone inmediatamente al tanto de todo lo que acontece en el mundo, alimentan malentendidos muchas veces peligrosos. 
En el 2005 la publicación de unas viñetas satíricas sobre Mahoma, de parte de un pequeño diario danés, incendió las plazas de decenas de países, desde Marruecos hasta Indonesia, causando muchos muertos. Algo parecido sucedió en el 2006, a propósito de un pasaje del discurso de Benedicto XVI en Regensburg. Las tendencias globalizantes y las de signo opuesto chocan al interior de los mismos grupos.

Hay momentos en que éstos sienten la diversidad como una amenaza, capaz de desencadenar enfrentamientos inútiles y anacrónicos. En otros momentos, en cambio, el peligro lo ven en la uniformización que lo nivela todo y destruye esa variedad que es lo más increíble y bello que la humanidad ha creado a lo largo de su extenso recorrido por la historia. En Francia las mujeres musulmanas que retoman el velo y defienden el derecho a llevarlo no son las ancianas, sino las jóvenes con educación superior. En otras palabras: existe una tendencia que privilegia la actitud a distinguir, conservar, especificar, separar y otra que aspira a volver universales valores, lenguajes y significados. Evidentemente las dos son legítimas y custodian valores a los que no sería sabio renunciar, siempre y cuando el juego no se escape de control y no se produzcan tragedias.

Mientras a ciertos niveles se prospecta el nacimiento de una cultura supranacional que parece unir grupos humanos y etnias que por siglos se combatieron, al interior de unos mismos grupos nacionales asistimos al desencadenarse de fuerzas centrífugas que, en nombre de las "raíces" -a veces más imaginarias que reales- lingüísticas, étnicas, sociales, religiosas diferentes, invocan privilegios y levantan barreras o implementan limpiezas éticas. La ex Yugoeslavia, como la región del Caucaso, son buenos ejemplos, pero no son los únicos. El excelente libro de Amin Malouf, 
Identidades asesinas ilustra los excesos a los que puede conducir la búsqueda exasperada de la identidad.

La cultura que difunden los medios de comunicación no ayuda a esclarecer el panorama. Si a veces exalta los particularismos, a nivel de jerga y de folklore, en otros momentos abandera las tesis de la universalidad, que tienen un encanto indiscutible para muchos jóvenes. Pero se trata de algo superficial: en el momento de la du$\mathrm{da}$, estos vuelven a buscar seguridad en las que parecen ser las únicas garantías de estabilidad: el grupo familiar y los modelos tradicionales de comportamiento.

\section{El otro}

Hasta el siglo XVI, los diferentes grupos humanos que poblaban la tierra vivían relativamente separados por grandes barreras naturales, como las cordilleras y los océanos y se relacionaban a través de contactos lentos y limitados. En el año 1492 comienza un proceso de integración, dentro de un único sistema, fundado en relaciones de dominación de parte de la supremacía europea. Su cultura se vuelve planetaria y se convierte en la unidad de medida; a las demás se las clasifica como avanzadas o atrasadas, en comparación con la civilización europea.

Según el búlgaro Tzvetan Todorov, "la conquista de América anuncia y funda nuestra identidad". Occidente adquiere una nueva conciencia de sí, no sólo por el contacto con el pasado, como había sucedido en las décadas del Renacimiento, sino con los nuevos "descubrimientos": las novedades que estos revelan ya no pueden clasificarse según las viejas categorías de origen bíblico ni con la cosmografía griega.

La aparición de humanidades diferentes plantea el problema de la alteridad y de la necesidad de entender- 
la. El primer contacto con el desconocido inquieta, causa admiración y estupor, es decir, interrumpe temporáneamente el juicio, suspende las referencias, y pone en discusión las fronteras de la propia identidad. Superado este primer momento, la reacción es la de combatirlo, asimilarlo o someterlo. El colonialismo no ha sido otra cosa que la actuación de esta última alternativa. Se supone que la época de las colonias debería haber terminado, pero se prolonga con infinitos otros instrumentos, como los medios de comunicación o los condicionamientos impuestos por la economía.

También la educación puede convertirse en un instrumento de dominación. De hecho, lo ha sido y lo sigue siendo. Las minorías étnicas que viven en el Ecuador y en los demás países reciben una escolarización que es normada por textos y programas que emanan de una Ministerio Central, expresión de la cultura dominante.

\section{Educar a la alteridad}

El proyecto educativo en las sociedades democráticas se basa en el principio de la igualdad: las instituciones deben proponerse brindar a todos los ciudadanos los mismos instrumentos de conocimiento. Es una aspiración difícil de realizar, aún en las sociedades más "desarrolladas", pero, no por eso, debe abandonarse.

Mas lo que se plantea hoy con frecuencia es también el derecho a la diferencia. Lo uno y lo otro no están en contradicción: se puede aspirar a la igualdad de oportunidades, pero, al mismo tiempo, se debe exigir que la educación no resulte destructora de las particularidades.

Aquí se inserta el discurso de la interculturalidad. Cuando hablamos de educación intercultural aludimos a una práctica basada en la interacción, el intercam- 
bio, la reciprocidad, la solidaridad. Evidentemente esto presupone que entren en juego culturas diferentes, cada una de las cuales tiene derecho a ser respetada. En la práctica está siempre al acecho el peligro que las diferencias se definan de una manera tan rígida que acaben deshilachando del tejido social.

Si cada grupo se convierte en un monolito, encerrado en el cultivo de sus diferencias, le resulta imposible captar las analogías que permiten convivir. $\mathrm{Al}$ absolutizar las diferencias se termina en el aislamiento, es decir se obtienen el mismo resultado que persiguen las políticas racistas.

A menudo se escucha que los migrantes deben hacer lo posible para que sus hijos no pierdan el contacto con sus raíces, pero, no por ello deben encerrarlos en un gueto lingüístico o de otro tipo.

Es lo que intentan hacer los Menonitas, a pesar de que se trata de un caso limitado y difícilmente proponible.

La Antropología Cultural puede ayudar a construir modelos educativos que permitan administrar los conflictos causados por la diversidad. En primer lugar nos sugiere que es indispensable distinguir entre valores fundamentales y diferencias culturales. Los primeros son aquellos en los que se fundamentan los principios morales, capaces de regular la conducta de cada individuo. Los segundos llegan a ser lo que los músicos llaman "variaciones sobre el tema" y fueron modulados por el recorrido histórico de cada grupo.

Las investigaciones antropológicas han revelado que la mayoría de los valores fundamentales son comunes a las diferentes culturas, esto revela que, acerca de ellos, existen más acuerdos que conflictos. Esto constituye una amplia base de consenso entre grupos diferentes. Es inevitable que surjan tensiones, pero para resolverlas, se aplica- 
rán los métodos propios de la confrontación y del debate democrático, sin dejar de tomar en cuenta que siempre hay alguien más débil y menos equipado para hacer valer sus argumentos, es decir, necesita ser tutelado. Durante el proceso educativo el toparse con la diversidad constituye un estímulo positivo, porque la identidad no se define sólo en base a lo que cada persona o grupo piensa de sí, sino también, y especialmente, por lo que los demás opinan de él.

Así las cosas, cambia del todo la manera de plantear el problema de la educación de las minorías. Es-
tas deben dejar de ser vistas como destinatarias de proyectos especiales, afrontados con cierta condescendencia y hasta compasión. Todo lo contrario con su existencia, su especificidad, su variedad; ellas estimulan nuevas maneras de enseñar, y obligan a los grupos que se consideran hegemónicos a dudar de sus seguridades.

\section{Redefinir la identidad étnica}

En la Grecia antigua, la palabra ethnos se la utilizaba en contraposición a polis y se refería tanto a los griegos no organizados en ciudades, como a los no-griegos (los Bárbaros). La polis, la ciudad-estado, era la comunidad bien estructurada, con leyes y buenas costumbres, mientras que ethnos era algo incompleto, que debía perfeccionarse.

Fue a finales del siglo XVII que el vocablo empezó a utilizarse en relación con la identidad nacional, entendida como una comunidad cohesionada, con un origen común y dotada de un patrimonio cultural propio.

Las administraciones coloniales tendieron a ver la etnia como algo estático y cerrado, que de alguna manera podía ser clasificado de acuerdo a las tareas administrativas. La última generación de antropólogos se topó 
con el fenómeno de las migraciones y la urbanización salvaje que convoca y mezcla una multitud de culturas diferentes. Se pasa de esta manera de ver la etnia como objeto cerrado de estudio, a analizar la etnicidad como sentido de pertenencia, vista desde el lado del sujeto. Entendida así, resulta un punto de partida para las reivindicaciones de determinados grupos. En esta visión de las cosas, la identidad étnica no se la ve ya como un conjunto social compacto y homogéneo; sino como algo relativo y situacional. La pertenencia deja de ser un dato "natural" para volverse una categoría del pensamiento. La etnicidad se convierte en una forma de interacción entre los grupos que se mueven en un contexto social común.

Hablando del Ecuador y limitándonos a la educación formal, se puede observar que en las grandes ciudades, donde hay una amplia oferta educativa y la presencia de una gran cantidad de instituciones particulares, las familias pueden evitar que los hijos, en edad escolar, tengan contactos con individuos de culturas diferentes (indígenas, "cholos"), escogiendo planteles, en los que por el alto costo de la pensión se da un nivel de estratificación.

En las poblaciones menores esto es menos fácil, como también para las clases populares, aunque muchos hacen lo posible y afrontan grandes gastos para buscar una escuela, de alguna manera, selectiva. Convirtiendo a la educación de esta manera en un instrumento para fijar y perpetuar la discriminación.

Es común el que los educadores se preocupen permanentemente por mejorar los métodos de enseñanza y alcanzar la excelencia al interior de su plantel, es más bien raro que miren con ojos críticos al sistema educativo del país, en su conjunto. No basta repetir que la educación debe ser obligatoria, laica y gratuita. Hay que tomar conciencia de que es evidentemente discriminante y no hace mucho para construir mentalidades verda- 
deramente democráticas. Pocos dirigentes de las organizaciones clasistas de los maestros tienen a sus hijos en planteles laicos, a los que por supuesto defienden con tanto fervor.

\section{Superar el etnocentrismo}

El antropólogo norteamericano William Graham Sumner (1840-1910) definió el etnocentrismo como "aquella visión del mundo según la cual un grupo se considera como centro del universo entero y a los demás los clasifica y avalúa en relación al mismo". El etnocentrismo está presente en todas las sociedades, representando una extensión del egocentrismo que se encuentra en la base de toda experiencia humana. El parentesco y sus extensiones simbólicas constituyen el esquema estructural que permite el paso del "yo" al "nosotros". Así el etnocentrismo, como dice el antropólogo Vittorio Lanternari, resulta ser "la necesidad instintiva de garantizar para sí una identidad social con respecto a la individual, y a la identidad humana en general".

El etnocentrismo tiende a manifestarse con el desprecio por quien es diferente y con el rechazo de lo que es ajeno o nuevo.

Debe ser la educación la que ayuda a que crezca la capacidad de crítica y el juicio autónomo. Lamentablemente ésta se reduce todavía a una identificación exclusiva con un patrimonio cultural definitivamente estructurado.

No se trata, como hacía notar E. De Martino (1908-1965) de subestimar o, peor, abandonar la propia cultura de origen (algo, por otro lado, imposible) sino de ser disponibles para reconocer el carácter limitado y parcial del propio patrimonio cultural y de buscar confrontarlo con la diversidad. 
A este respecto es urgente revisar el lenguaje de muchos textos de historia y de cívica que revelan un chauvinismo insoportable.

A veces el etnocentrismo encubre con dificultad una mentalidad racista. Los discursos oficiales niegan y rechazan el racismo, pero este se manifiesta de muchas otras maneras, por ejemplo en los chistes y los insultos.

\section{Educar para un mundo complejo}

Las migraciones han existido siempre. ¿Qué es la Biblia, sino el libro que nos narra las innumerables trashumancias de un pueblo beduino y su difícil sedentarización en Palestina, interrumpida por largos exilios y, después, por una diáspora que diseminó a los judíos por todo el mundo conocido?

Movidos por la búsqueda de mejores tierras, empujados por el desplazamiento de otros grupos o motivados por el deseo de mejorar sus condiciones de vida, los seres humanos nunca han dejado de migrar. Lo que hoy aparece como nuevo son las dimensiones del fenómeno. Estos desplazamientos masivos, la acción de los medios de comunicación, los nuevos lenguajes tecnológicos que se van conformando, partiendo del inglés, son los que determinan nuevas dimensiones de la identidad y de la cultura, en los que conviven elementos traídos de diferentes orígenes que se suman con los de la comunidad receptora y otros, frutos de síntesis y yuxtaposiciones. La identidad se construye y se construirá siempre más en la movilidad. Este hecho al momento es visto más como una fuente de inseguridad que como una riqueza: lo revela el aumento de la xenofobia en casi todos los países con altas tasas de inmigración. La educación debe ayudar a afrontar esta situación nueva, contribuyendo a descubrir "el otro que hay en nosotros". El objetivo es superar la noción 
exclusivista del "nosotros", apuntando a una relativización que proponga nuevos paradigmas educativos.

La educación debe hacer referencia a estas dimensiones de la globalidad y desarrollar en los alumnos habilidades de pensamiento que contribuyan a cambiar las actitudes y corregir los prejuicios. Debe proponer un tipo de conocimiento que supere la concepción tradicional del saber como la adquisición de habilidades, desarrollando, en su lugar, la capacidad de afrontar conexiones complejas entre conceptos.

Un proyecto educativo que tiene como horizonte formar a los sujetos para convivir en un mundo complejo representa una oportunidad para revisar los métodos pedagógicos y construir una nueva visión del hombre.

\section{Preparar para el cambio}

Históricamente, la educación formal, impulsada por el Estado, ha constituido la gran herramienta para formar en los alumnos el sentido de pertenencia al país, a esto se lo suele llamar "amor a la Patria". Es una operación absolutamente legítima, siempre y cuando no encubra actitudes opresivas. Un ejemplo claro lo tenemos en nuestro país: En el Ecuador se exalta como una riqueza la multiplicidad de las culturas, pero, de hecho, la escuela ha trabajado siempre para destruirla, homologando la variedad en un único modelo. Las características de los diferentes grupos se exaltan folklorizándolas y sus manifestaciones se reducen a representaciones ocasionales, en las que los participantes "se disfrazan" de indios de las distintas etnias.

Todo esto puede ser inevitable, mas debe quedar claro que la convivencia entre diferentes no debería desembocar en una operación que mezcle todos los in- 
gredientes para obtener un producto híbrido, sino en un esfuerzo por promover una interacción activa entre modelos culturales diferentes. Respetar al otro no es simplemente tolerarlo, sino reconocerle una dignidad plena: es importante saber que, valorando al que es distinto, cada uno aprende a valorarse a sí mismo, como portador de diversidad.

Una de las preocupaciones de este enfoque educativo es la de luchar contra la exclusión. A menudo ésta asume el aspecto de la autoexclusión, que nace de complejos de inferioridad.

La escuela debería ser el laboratorio donde se ensaya el tipo de sociedad que se quiere construir, tanto más que a nivel local; a menudo la escuela es la única instancia en condición de promover la integración sociocultural en el territorio. En una sociedad pluralista, la educación intercultural se vuelve una necesidad dada la enorme movilidad de hombres y de bienes y por el crecimiento exponencial de las comunicaciones. Caminamos hacia un tipo de sociedad en que sólo una educación intercultural podrá ser una educación completa, en cuanto la única capaz de superar el "pensamiento cerrado". Su característica es formar para el cambio, entendido éste como una actitud de búsqueda permanente que lleva a relativizar los conocimientos, para encontrar soluciones nuevas.

\section{Conclusión}

Estas reflexiones no pretenden presentar un cuadro completo de los puntos de posible interacción entre ciencias de la educación y ciencias antropológicas. Sus destinatarios son los educadores y lo único a que aspiran es a crear en ellos algo más que un interés pasajero por la temática de la cultura y la inmensa variedad de formas bajo las cuales se presenta. No se trata de una curiosidad teó- 
rica, sino de la necesidad de formar a los niños y jóvenes para el mundo en que les tocará vivir.

El Ecuador ha sido siempre un país multicultural, pero es ahora que esto se vuelve un desafío, porque los varios grupos se desplazan, entran en contacto, reclaman espacios, respeto y la posibilidad de tomar decisiones sobre temas que les conciernen. Hablo de los grupos autóctonos y también de los nuevos inmigrantes, siempre más numerosos. El mismo problema, pero en situaciones invertidas lo viven centenares de ecuatorianos que han viajado a otros países.

También el mundo ha sido siempre multicultural, pero, si no se preparan las jóvenes generaciones para afrontar con sapiencia el hecho con las características que ha asumido últimamente, esto se puede convertir en fuente de enfrentamientos incontrolables.

\section{Bibliografía}

ALVAREZ GONZALEZ, F.,

2000 Las derivas de la alteridad. Edit. por el autor.

AA. VV.

1970 Introducción a la cultura africana en América Latina. UNESCO, París.

avec PORCHER, L

1996 Education et communication interculturelle, Presses Universitaires de France, Paris.

AMSELLE, J.L.

1990 Logiques métisses. Anthtopologie de l'identité en Afrique et ailleurs, Payot, Paris.

DESINAN, C

1998 Orientamenti di educazione interculturale, Franco Angeli, Milano

LANTERNARI, $\mathrm{V}$

1983 L'incivilimento dei barbari, Dedalo, Bari.

LÉVI - STRAUSS, C

1967 Razza, storia e altri studi di antropologia, Einaudi, Torino. 
MOYA, R; MOYA A,

2004 Derivas de la interculturalidad, caflis/Fernandez, Quito.

TAGUIEFF, P.A

1995 Les fins de l'antiracisme, Editions Michalon, Paris TODOROV, T

1984 La conquista dell'América. Il problema dell' altro, Einaudi, Torino 